\title{
Correction to: Inflammaging phenotype in rhesus macaques is associated with a decline in epithelial barrier-protective functions and increased pro-inflammatory function in CD161-expressing cells
}

\author{
Edith M. Walker • Nadia Slisarenko • Giovanni L. Gerrets • Patricia J. Kissinger • \\ Elizabeth S. Didier • Marcelo J. Kuroda • Ronald S. Veazey • S. Michal Jazwinski • Namita Rout
}

Published online: 28 December 2019

(C) American Aging Association 2019

\section{Correction to: GeroScience \\ https://doi.org/10.1007/s11357-019-00099-7}

Unfortunately, the original version of this article was published with error in the materials and methods section.

Under the sub-heading "Rhesus macaques and blood sampling", the text incorrectly states that blood was centrifuged at $14000 \mathrm{~g}$ for $5 \mathrm{~min}$ at $4{ }^{\circ} \mathrm{C}$ and plasma aliquots were cryopreserved at $-80^{\circ} \mathrm{C}$ until used. Similarly, under

The online version of the original article can be found at https://oi. org/10.1007/s11357-019-00099-7

E. M. Walker · N. Slisarenko • G. L. Gerrets • N. Rout $(\square)$ Division of Microbiology, Tulane National Primate Research Center, Covington, LA, USA

e-mail: nrout@tulane.edu

P. J. Kissinger

School of Public Health \& Tropical Medicine, Tulane University, New Orleans, LA, USA

\section{E. S. Didier · M. J. Kuroda}

Center for ComparativeMedicine and California National Primate

Research Center, University of California Davis, Davis, CA, USA the sub-heading "Quantification of circulating markers of inflammation, microbial translocation, and intestinal damage" EDTA-preserved plasma samples were centrifuged $\left(14,000 \mathrm{~g}\right.$ for $5 \mathrm{~min}$ at $\left.4{ }^{\circ} \mathrm{C}\right)$ and aliquots were frozen at $-80^{\circ} \mathrm{C}$ until used.

The correct centrifugation for isolation of plasma should be: $1,000 \mathrm{~g}$ for $5 \mathrm{~min}$ at $4{ }^{\circ} \mathrm{C}$.

R. S. Veazey

Division of Comparative Pathology, Tulane National Primate Research Center, Covington, LA, USA

S. M. Jazwinski · N. Rout

Tulane Center for Aging, Tulane University, New Orleans, LA, USA 